\title{
The 2015 Fillmore Earthquake Swarm and Possible Crustal Deformation Mechanisms near the Bottom of the Eastern Ventura Basin, California
}

\section{by Egill Hauksson, Jennifer Andrews, Andreas Plesch, John H. Shaw, and David R. Shelly}

\begin{abstract}
The 2015 Fillmore swarm occurred about $6 \mathrm{~km}$ west of the city of Fillmore in Ventura, California, and was located beneath the eastern part of the actively subsiding Ventura basin at depths from 11.8 to $13.8 \mathrm{~km}$, similar to two previous swarms in the area. Template-matching event detection showed that it started on 5 July 2015 at 2:21 UTC with an $M \sim 1.0$ earthquake. The swarm exhibited unusual episodic spatial and temporal migrations and unusual diversity in the nodal planes of the focal mechanisms as compared to the simple hypocenterdefined plane. It was also noteworthy because it consisted of $>1400$ events of $M \geq 0.0$, with $M 2.8$ being the largest event. We suggest that fluids released by metamorphic dehydration processes, migration of fluids along a detachment zone, and cascading asperity failures caused this prolific earthquake swarm, but other mechanisms (such as simple mainshockaftershock stress triggering or a regional aseismic creep event) are less likely. Dilatant strengthening may be a mechanism that causes the temporal decay of the swarm as pore-pressure drop increased the effective normal stress, and counteracted the instability driving the swarm.
\end{abstract}

Online Material: Tables of earthquake detections, relocations, and focal mechanisms, and animation of swarm seismicity evolution in time.

\section{INTRODUCTION}

Earthquake swarms that occur in a variety of tectonic settings in southern California can be characterized by onsets ranging from gradual to fast, lack of a prominent mainshock, and different styles of migration over time and space (e.g., Vidale and Shearer, 2006). Tectonic swarms are often interpreted as being either related to movement of fluids in the crust or, in some cases, related to aseismic creep events causing localized changes in stress (Roland and McGuire, 2009).

The greater Ventura region is characterized by an elevated rate of background seismicity that is, in part, driven by rapid tectonic convergence $(\sim 7 \mathrm{~mm} / \mathrm{yr})$ in the region (Marshall et al., 2013). Background seismicity from 1981 to 2015, with average rate of approximately five $M \geq 3$ events per year, is mostly located on the north side of the Ventura basin (Fig. 1). In contrast, the 2015 Fillmore swarm provided a unique opportunity to study tectonic deformation processes at depth below the basin sediments. In particular, the recorded seismicity may reflect geologic processes at depth, including release of fluids caused by metamorphic dehydration (Ague et al., 1998), fluid migration, and cascading asperity failures along a detachment zone.

The east-west-trending Ventura basin is the deepest of several Cenozoic sedimentary basins in the Transverse Ranges province of southern California (Yeats, 1976). The eastern half of the basin is bounded by the San Cayetano fault to the north and the Oak Ridge fault to the south (Fig. 1). The ongoing subsidence and infill of sediments in the Ventura basin suppresses the crustal isotherms and results in low heat flow, as low as $43 \mathrm{~mW} / \mathrm{m}^{2}$ (DeRito et al., 1989). The suppressed isotherms in the Ventura region are also consistent with unusually deep seismicity beneath the basin (Bryant and Jones, 1992); both mainshock-aftershock sequences and small swarms occur down to depths of 25-30 km.

Previously, Vidale and Shearer (2006) identified 71 earthquake clusters in southern California, each consisting of more than 39 earthquakes. They analyzed spatial, temporal, and magnitude features of these 71 earthquake clusters and showed that 19 sequences were swarm like. They favored pore-fluid pressure fluctuations as the mechanisms most likely responsible for seismicity bursts, although they suggested that, in some 


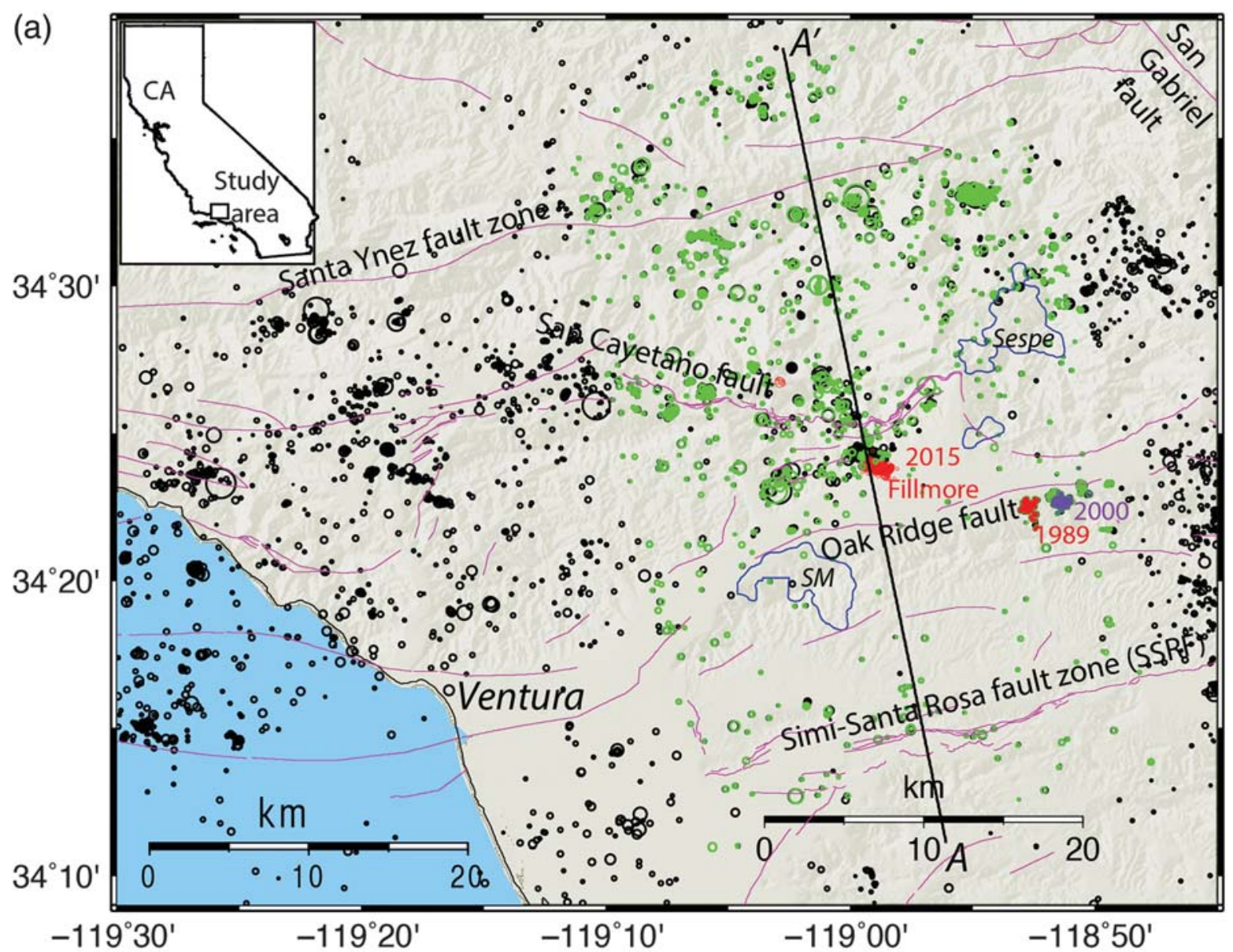

(b)

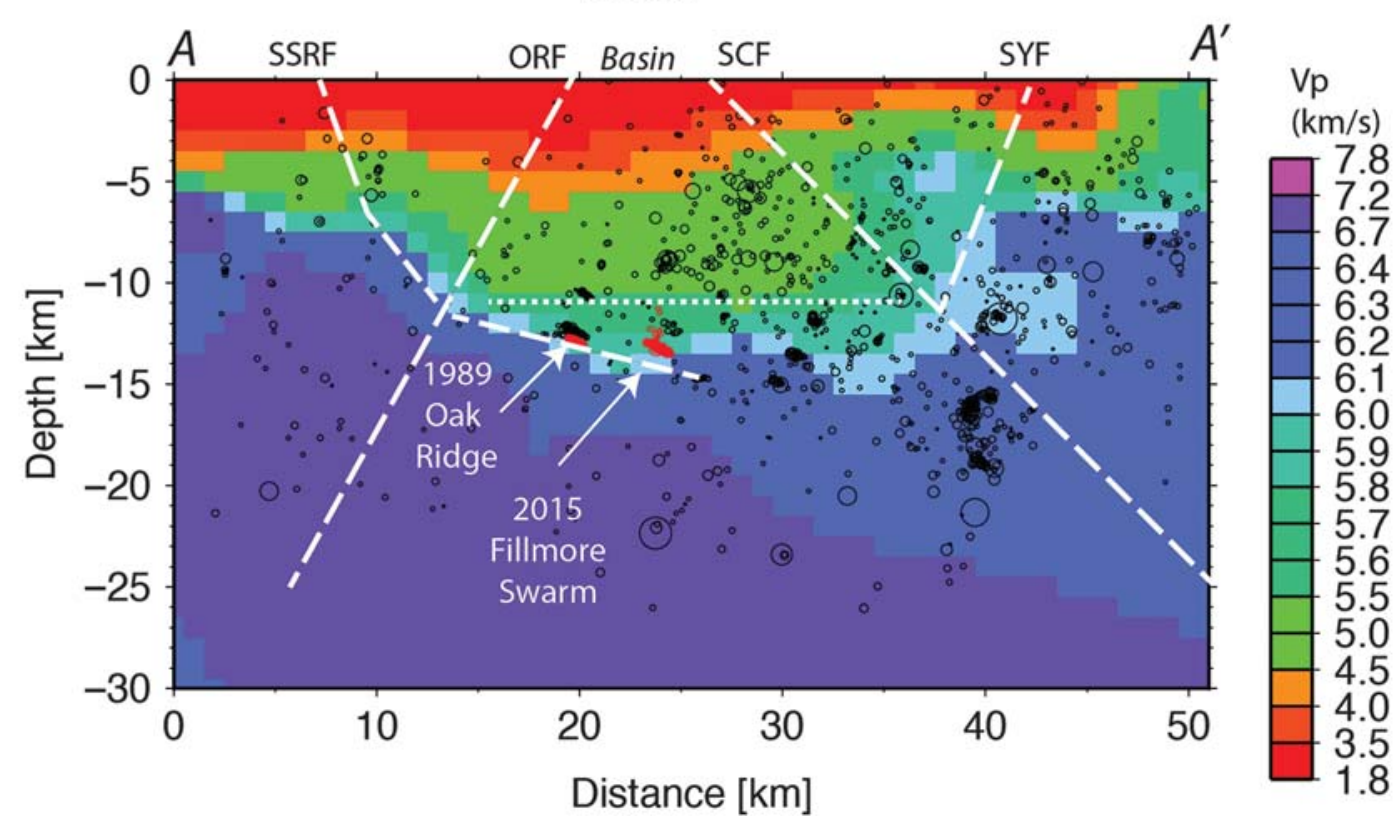

A Figure 1. (a) Map and (b) cross-section views of regional seismicity, with events in the cross section plotted in green on the map. Outlines for three oilfields (South Mountain [SM], Sespe, and Fillmore) are shown. The cross section shows the modified 3D $V_{P}$ model from Shaw et al. (2015) and the approximate locations of late Quaternary faults in the cross section from the Southern California Earthquake Center-Community Fault Model (SCEC-CFM) (Plesch et al., 2007; Marshall et al., 2013; Nicholson et al., 2014). The 1989 and 2015 swarms are plotted in red, and the 2000 swarm is shown in purple in the map view. Location of study area within California is shown in upper left corner as a rectangle. 
cases, aseismic slip could play a role. In addition, Chen and Shearer (2011) studied earthquake swarms in the Salton trough area and obtained a hydraulic diffusion coefficient of $\sim 0.25 \mathrm{~m}^{2} / \mathrm{s}$ for the Salton Sea geothermal area. They found migration velocities from 0.008 to $0.8 \mathrm{~km} / \mathrm{hr}$ and argued that, if the migration velocities exceeded $0.1 \mathrm{~km} / \mathrm{hr}$, fluid diffusion is not rapid enough and therefore that other processes, such as creep or slow-slip events, are required to explain the seismicity.

Two other small earthquake swarms have occurred in the Ventura region since improved seismic monitoring became available in 1981. First, a swarm of 50 earthquakes of $M$ 1.2-1.8 occurred near the southeast corner of the basin, about $8 \mathrm{~km}$ south-southeast of Fillmore, in May 1989. It exhibited similar spatial and temporal behavior as the 2015 swarm (Shearer, 1998). Second, Chen et al. (2012) also identified a comparable swarm in 2000 , located adjacent to the 1989 Oak Ridge swarm.

This high-resolution seismological study involves a very small crustal volume of $1.5 \mathrm{~km} \times 0.5 \mathrm{~km} \times 2 \mathrm{~km}$. When compared with a $90-\mathrm{km}$-long $1992 M_{\mathrm{w}} 7.3$ Landers rupture, this cluster would be a mere dot on an aftershock map, and therefore the swarm does not contribute significantly toward understanding the broader regional tectonics. However, because the California Institute of Technology (Caltech)/U.S. Geological Survey Southern California Seismic Network (SCSN) seismic station density is higher than in the past, and the digital data are of higher quality, we are able to apply new data analysis techniques to resolve intricate spatial and temporal details of the crustal deformation processes and to explore the possible driving mechanisms for such sequences.

\section{DATA PROCESSING}

The background seismicity (1981-2015) and the 2015 Fillmore sequence were recorded by the SCSN and relocated using waveform cross correlation and refined $3 \mathrm{D}$ velocity models as described by Hauksson et al. (2012).

The SCSN routine picker and association algorithms identified about 227 events from 5 July until late September 2015. Initially, the SCSN used a 1D model with station corrections to determine the hypocenters for the events. Second, we used SIMULPS to calculate absolute errors for the hypocenters of $\sim 0.5 \mathrm{~km}$, which depend on availability of the $P$ and $S$ picks as well as on the details of the complex $3 \mathrm{D}$ velocity model (Thurber, 1993). Third, we relocated the events of $M \geq 1.0$ using both absolute and differential travel times determined with waveform cross correlation. We used the new version of hypoDD that uses a 3D velocity model from traveltime calculations to determine the hypocenters (Waldhauser and Ellsworth, 2000). We resampled the 3D $V_{P}$ and $V_{P} / V_{S}$ model $(10 \mathrm{~km} \times 10 \mathrm{~km}$ horizontal grid spacing, with $4 \mathrm{~km}$ grid spacing in depth down to $32 \mathrm{~km}$ depth) described by Shaw et al. (2015), which was slightly modified by allowing local seismicity to adjust the model. Finally, by applying a singular-value decomposition technique in hypoDD, we determined the relative errors, which are less than $6 \mathrm{~m}$ horizontally and $12 \mathrm{~m}$
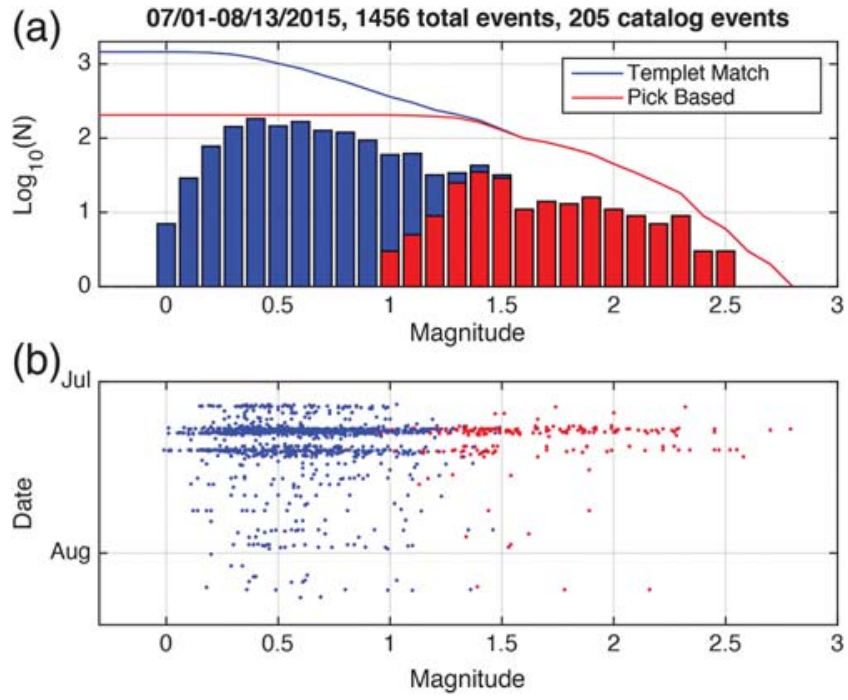

A Figure 2. (a) Southern California Seismic Network (SCSN)detected events (pick-based [PB]-events) cumulative (red line); SCSN-detected and waveform-detected cumulative (TM-events) (blue line); and binned (bars) numbers of events in the 2015 Fillmore swarm versus magnitude. SCSN-detected events are shown in red, whereas the template-matching events are shown in blue bins. We used ZMAP (Wiemer, 2001) to determine $b$-values that range from 0.86 to 1.01 (for magnitude of completeness, $M_{\mathrm{c}} 0.8$ and 1.4), which is similar to the average $b$-value for southern California (Hutton et al., 2010). (b) The temporal distribution of the swarm versus magnitude using the same color scheme.

vertically (ㅌ) Table S1, available in the electronic supplement to this article).

To extend the SCSN catalog to lower magnitudes $(M \sim 0)$, we applied template matching using the waveforms of SCSN-detected events as templates, following the method described by Shelly, Hill, et al. (2013) and Shelley, Moran, and Thelen (2013). More than 1200 additional events were identified that could be precisely located (those retaining at least 15 correlation differential times for both $P$ and $S$ waves after inversion). The absolute depths of these events were adjusted to match the average depth of the SCSN-relocated events. The pick-based (PB) and template-match (TM) events complement each other in detail. The smallest TM events range down to $M 0$, whereas the $\mathrm{PB}$ events range up to $M 2.8$. In the magnitude range from 1.0 to 1.5 , events detected by both the PB and TM methods contribute to the cumulative total, demonstrating the detection capability of the PB algorithm (Fig. 2). The magnitudes of the TM events were determined by calibrating the amplitudes for the events using the SCSN local magnitudes $\left(M_{\mathrm{L}}\right)$ (Uhrhammer et al., 2011), extending this scaling for smaller-magnitude events (ㅌ) Table S2).

Focal mechanisms were determined with the HASH search method (Hardebeck and Shearer, 2003) as applied by Yang et al. (2012). The HASH method returns the most likely set of mechanisms after taking into account various sources of 

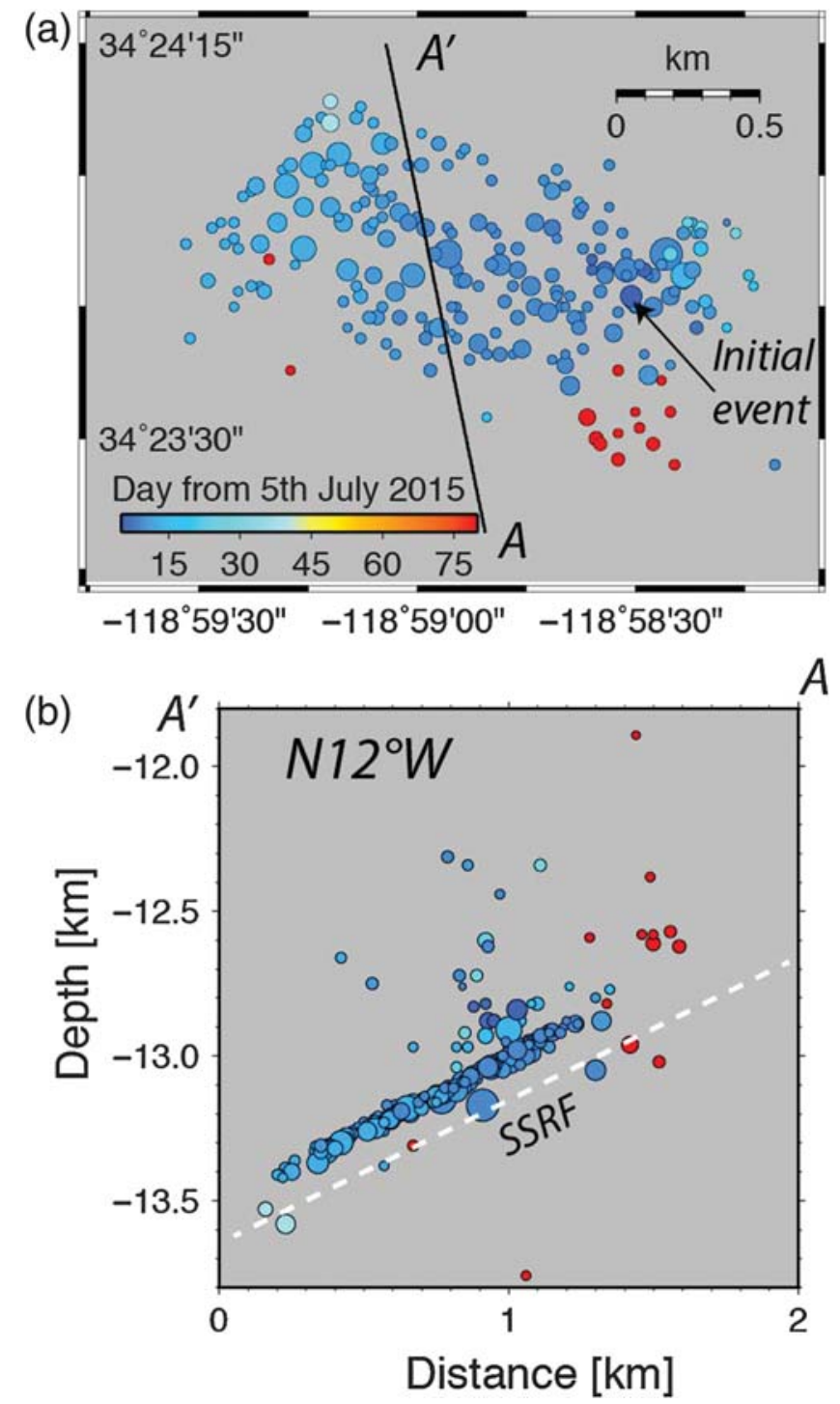

$\Delta$ Figure 3. (a) Detailed map view and (b) cross section of the 227 SCSN-relocated hypocenters; changes in color show the temporal and spatial migration. The cluster of hypocenters forms $<50-$ m-thick plane dipping $26^{\circ}$ to $\mathrm{N} 12^{\circ} \mathrm{W}$. The inferred location of the Simi-Santa Rosa fault (SSRF) zone is shown as a white dashed line (Nicholson et al., 2014).

uncertainty, such as several possible $1 \mathrm{D}$ velocity models. We included both first-motion polarities and $S / P$ amplitude ratios to constrain the nodal planes. A total of 41 focal mechanisms were determined for events of $M \geq 2$ (ㅌ) Table S3). These focal mechanisms are well constrained and have average root mean square angular difference of all planes or uncertainty of less than $30^{\circ}$, which indicates high-quality mechanisms (Hardebeck and Shearer, 2003).

\section{RESULTS}

The 1981-2015 Ventura seismicity that is scattered throughout the Ventura region includes several swarms, but none have been as prolific as the 2015 Fillmore swarm. Many of the seismicity clusters that follow the San Cayetano fault are elongated in a west-northwest direction, with the seismicity extending to greater depths to the north. The spatial distribution of the Fillmore hypocenters was also elongated in a west-northwest direction (Fig. 3).

The 1989 and 2000 Oak Ridge and the 2015 Fillmore swarms occurred toward the south and north edges of the eastern Ventura basin, respectively. The three swarms are probably located beneath the bottom of the actively subsiding basin. Moreover, the 2015 Fillmore swarm is located in the immediate vicinity of the inferred depth extension of the Simi-Santa Rosa fault (SSRF), as described by Nicholson et al. (2014) and represented in the Southern California Earthquake Center's Community Fault Model (CFM 5.0) (Plesch et al., 2007). The principal slip zone of the fault, where major earthquakes would occur, may have played a role in accommodating fluid migration or aseismic creep to facilitate stress loading of small adjacent asperities.

\section{Time-Space Evolution}

The Fillmore swarm expanded mostly down-dip from east to west in map view, but low levels of activity continued through the duration of the swarm near its origin (Figs. 3 and 4; see also (E) Animation $\mathrm{S} 1$ ). The $\mathrm{N} 12^{\circ} \mathrm{W}$-trending cross section shows a dipping zone of seismicity no wider than $50 \mathrm{~m}$, extending across an area of approximately $1 \mathrm{~km} \times 1.5 \mathrm{~km}$, in the $11.8-13.8 \mathrm{~km}$ depth range. The swarm defines a remarkably planar zone dipping $26^{\circ}$ to $\mathrm{N} 12^{\circ} \mathrm{W}$. There is also some indication of a second, less-active plane about $\sim 100 \mathrm{~m}$ above the main plane of the hypocenters.

The 2015 Fillmore swarm activity peaked on 9 and 10 July, with the largest event of $M 2.8$, and continued with several smaller spurts of activity, and tapered off in late July to late September. The overall spatial and temporal evolution of the sequence consisted of two distinct episodes of westerly downdip migration of the swarm events (Fig. 4). The main cluster is shown in light blue to green, whereas the late cluster is shown in red. In cross-section view, the 5-10 July burst occurred across most of the activated zone. On 13-14 July, the west down-dip edge was activated. From the end of July until late September, the activity had resumed again at the initiation point, becoming increasingly more scattered toward the end of the sequence (see also (E) Animation S1). In comparison, the 1989 swarm, consisting of 50 events with the largest event of $M$ 2.2, was located $\sim 8 \mathrm{~km}$ to the south-southwest near Oak Ridge (Shearer, 1998). Its spatial-temporal migration was different, with the 1989 swarm outlining a more circular zone of deformation (Shearer, 1998).

The detailed evolution of the Fillmore swarm with time, distance from first event, and focal depth shows the two main spurts of activity superimposed on a steady background rate near the origin of the swarm (Fig. 4). The swarm had a lowlevel onset lasting for approximately four days. The major spurt of activity occurred around 9 and 10 July. The second spurt occurred around 14 July. Several small spurts continued near the point of initiation to late September. Assuming a stress drop 


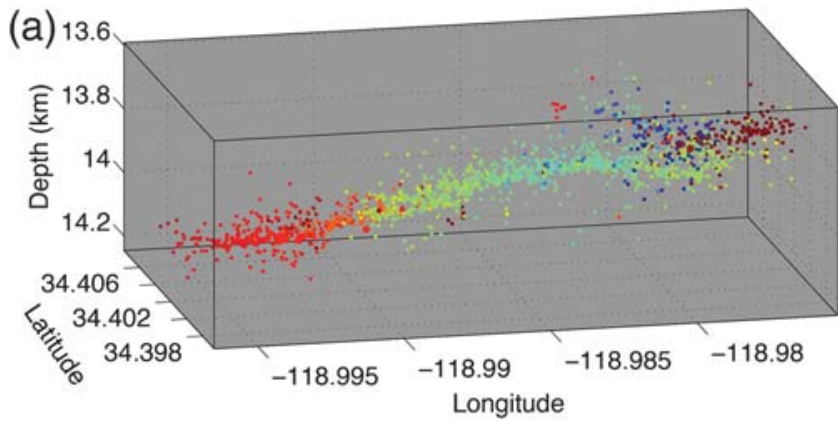

(b)
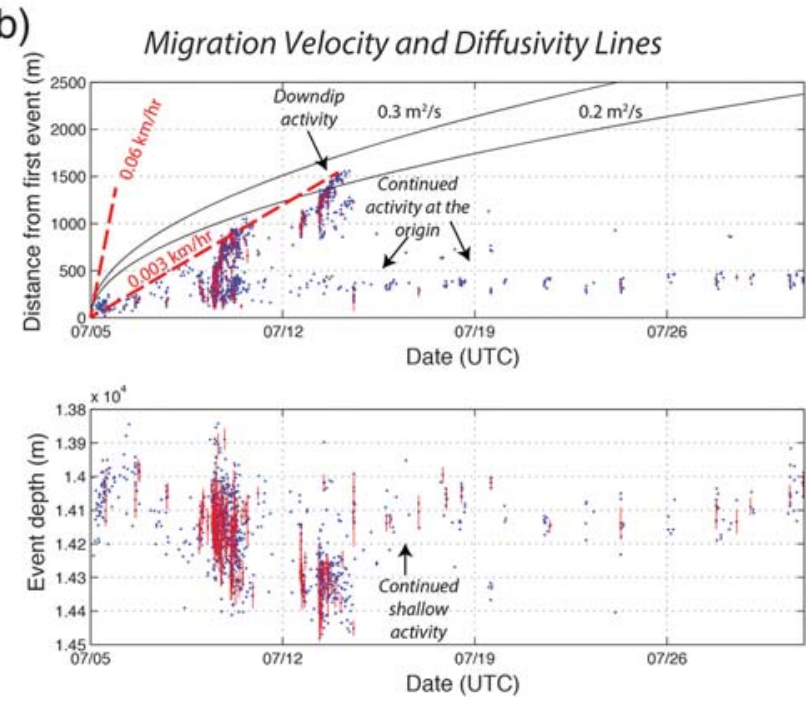

- Figure 4. (a) The spatial and temporal evolution of the whole swarm (1456 events), including template-match-detected events, showing down-dip migration. The size of the circles is scaled with magnitude, and color is by date in July 2015. (b) Spatial and temporal development of the swarm using distance from the first event and event depth relative to the first event versus event date. Curved lines indicate reference hydraulic diffusivities, according to the model of Shapiro et al. (1997), $r=\sqrt{(4 \pi D t)}$, which assumes homogeneous 3D diffusion. Red vertical lines indicate approximate rupture dimension for earthquakes of at least $M 1.0$, assuming a circular rupture and a $3 \mathrm{MPa}$ stress drop. Red dashed sloping lines indicate migration velocities as labeled.

of $3 \mathrm{MPa}$, the rupture lengths for the largest events are on the order of $200-300 \mathrm{~m}$. The diffusivity curves fit to the whole swarm suggest an overall rate of diffusivity of $0.2-0.3 \mathrm{~m}^{2} / \mathrm{s}$ when assuming a 1D model (Malagnini et al., 2012). The rate of event migration is significantly higher for the two main clusters $(\sim 0.06 \mathrm{~km} / \mathrm{hr})$ as compared with a rate of $0.003 \mathrm{~km} / \mathrm{hr}$ for the whole sequence, showing that at least two different time constants seem to be required to match the time-space evolution. The best-fit overall diffusivity curves indicate that the swarm migration was consistent with plausible fluid movement rates, whereas the behavior of the two clusters suggest cascading asperity failures and complex feedback with deformation in the area where the swarm originated. (a)

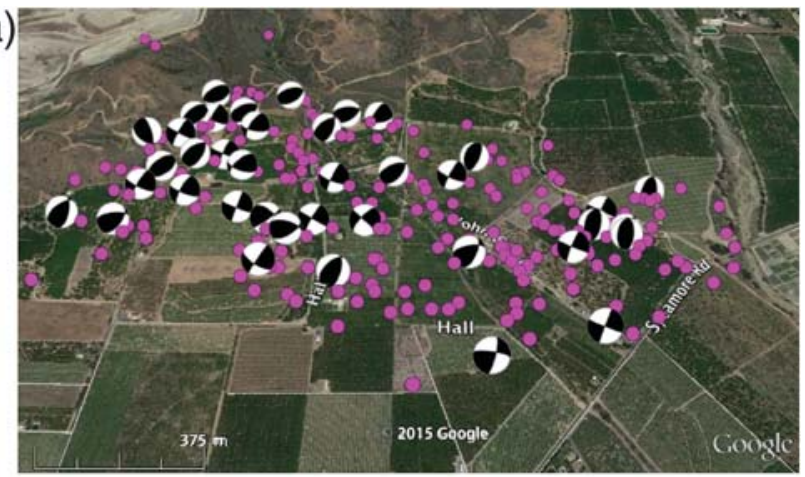

(b)

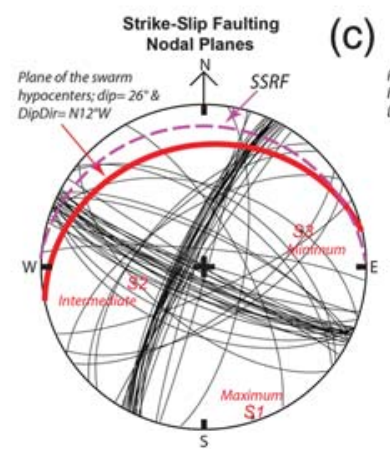

(c)

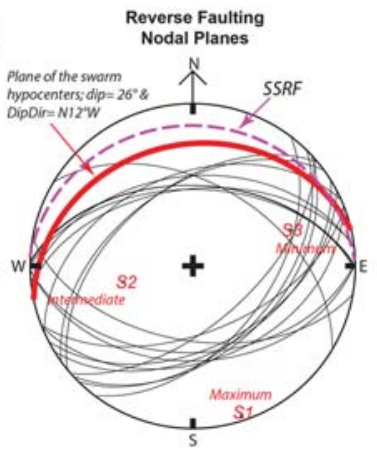

A Figure 5. (a) Screenshot of Google Earth image, showing epicenters in magenta, and 71 lower-hemisphere focal mechanisms of $A$ and $B$ quality for $M \geq 2.0$ events, which predominantly exhibit strike-slip motion. The scale bar of $375 \mathrm{~m}$ in lower left corner. (Background Image Landsat (C2015 Google Earth; see Data and Resources.) (b) Strike-slip and (c) reverse nodal planes, the plane of the swarm (red), the orientation of the SSRF zone is shown as a dashed plane (magenta), and the orientations of the three principal stresses axes are also shown (red).

\section{State of Stress and Effective Stress Drop}

A total of 31 focal mechanisms that were determined using first motions and $S / P$ amplitude ratios exhibited strike slip, whereas 10 exhibited thrust faulting (Fig. 5). To compare the orientation of the hypocenter plane with the nodal planes of the focal mechanisms, we separated out the reverse mechanisms (with rakes from $45^{\circ}$ to $135^{\circ}$ ) from the remaining strike-slip mechanisms. Within uncertainties, all of the nodal planes are inconsistent with the geometrical plane of the swarm, which more closely follows the orientation of the SSRF zone (Plesch et al., 2007; Nicholson et al., 2014). This suggests the presence of secondary faults, perhaps related to asperities, with strain or slip partitioning between high-angle strike-slip faults and moderately dipping thrust faults. The heterogeneity in the mechanisms suggests that the microseismicity may have occurred within or adjacent to a possibly fluid-filled fault or detachment zone, perhaps the SSRF or a fault splay in its hanging wall, about $1.7 \mathrm{~km}$ below the sediment-basement contact (Shaw et al., 2015). Elevated fluid pressures along detachment zones have been documented in many other tectonic settings (Hubbert and Rubey, 1959; Davis et al., 1983; Behrmann et al., 1988; Bilotti and Shaw, 2005). 
We inverted the focal mechanism data for the state of stress using the Michael (1984) stress inversion technique (Fig. 5). The stress state is similar to that obtained by Yang and Hauksson (2013), with the maximum principal stress trending $\mathrm{N} 162^{\circ} \mathrm{E}$. The intermediate and minimum principal axes have rakes consistent with a mixture of strike-slip and reverse faulting. The angle between the hypocenter plane and the maximum principal stress plane is $\sim 23^{\circ}$, whereas the angle with the reverse nodal planes is $\sim 40^{\circ}$ and the strike-slip nodal planes are slightly larger $\left(\sim 40^{\circ}\right.$ to $\left.\sim 45^{\circ}\right)$. This suggests that the seismicity is caused by heterogeneous volumetric deformation that includes both horizontal shear and compressional deformation adjacent to a dipping plane. Such crustal deformation zones are also often referred to as fault meshes (Hill, 1977; Sibson, 1996) and may also reflect fault damage zones.

It was not possible to determine reliable stress drops for individual events because of the small magnitudes of the events, the consequential limited signal-to-noise ratio in the seismograms, and the availability of data from only two nearby stations. To facilitate comparison with other swarms, we used the approach of Chen et al. (2012) to determine a different quantity, called the effective seismic stress drop for the sequence, which is defined as the ratio of total seismic moment release divided by the volume of the burst with radius $r$ :

$$
\Delta \sigma_{\text {quasi }}=\frac{7 \sum_{i}^{n} M_{o}^{i}}{16 r^{3}}
$$

We assume that $M_{\mathrm{w}}=0.9 M_{\mathrm{L}}+3.5$ for these small events (from the second formula in fig. 7e in Clinton et al., 2006, which corresponds to almost the same geographical region). The seismic moment $\left(M_{0}\right)$ for each event was determined using the standard empirical relation between $M_{\mathrm{w}}$ and $M_{0}$ (Clinton et al. 2006). The total seismic moment release was determined by summing up the moments for all the events and was equivalent to $M 3.6$. We assumed a faulting volume of $1.5 \mathrm{~km} \times 0.75 \mathrm{~km} \times 0.2 \mathrm{~km}$ and used an elasticity constant of $30 \mathrm{GPa}$ to determine an effective seismic stress drop of $0.6 \mathrm{MPa}$. Although this value should not be compared to the stress drop of individual events, it is close to the median values obtained by Roland and McGuire (2009) and Chen et al. (2012) for other swarms, such as the Brawley, Obsidian Buttes, and Salton trough sequences in the Imperial Valley of southern California. Creep events have been shown to have similar effective stress drops (Brodsky and Mori, 2007). Therefore, the low effective-stress-drop behavior, as for geothermal swarms, is consistent with the presence of fluids.

\section{Possible Crustal Deformation Mechanisms}

We speculate that the occurrence of the 2015 Fillmore swarm was caused by a combination of three possible mechanisms: metamorphic dehydration that releases water, fluid migration along a detachment zone, and cascading asperity failures along a detachment zone. The first two proposed mechanisms would represent a natural hydrofracture or hydroshear event. Presumably slow, ongoing metamorphic dehydration reactions generate fluids, and natural hydroshear events are generated when the fluid pressures exceed the strength of local asperities or faults.

In anthropogenic hydrofracturing experiments, fluids are injected to break the host rock. The associated fluid flow and stress changes can cause seismicity extending well beyond induced fractures (Raleigh et al., 1976). A hydroshear event beneath the Ventura basin could be caused by the mostly north-directed tectonic compression and by fluid generation as sediments subside while undergoing diagenesis and subsequent prograde metamorphism (Yardley and Bodnar, 2014). As fluids are expelled during diagenetic or metamorphic processes near the bottom of the basin, they could migrate toward the deeper crystalline basement, which can be a sink through hydration reactions (Yardley and Bodnar, 2014), due to the presence of seals (impermeable zones) in the overlying sediments (Obligado et al. 2002; Winterer and Durham, 1962). Décollement surfaces, such as the SSRF, often form in zones of locally elevated fluid pressures (Hubbert and Rubey, 1959; Davis et al., 1983; Behrmann et al., 1988; Bilotti and Shaw, 2005) and can provide pathways for fluid migration. In addition, fluids along these detachments could migrate upward along steeply dipping faults toward regions of lower fluid pressure. Such migration could explain the spatial and temporal evolution of the sequence through transient increase in porepressure loading of local asperities failing in small earthquakes. Loading of a random spatial distribution of asperities of different size and strength can also lead to cascading failures with different delay times, which may explain the burst behavior of the Fillmore swarm (Amitrano, 2003). Subsequently, the swarm quickly decays because failure of these asperities relaxes the fluid pressures along the detachment as fluids migrate into these regions of lower fluid pressure along faults.

Modeling of crustal dehydration processes also implies that the Fillmore swarm could be associated with metamorphic dehydration. The swarm likely occurred within upper Cretaceous metasediments that are overlain by a thick Cenozoic sedimentary section (e.g., Winterer and Durham, 1962) suggesting the presence of fluids in the hypocentral zone. Ague et al. (1998) applied a 1D model of coupled heat and fluid transport, porosity feedback, and metamorphism to investigate dehydration during burial of hydrous rocks. In particular, they investigated the temporal evolution of pore pressure and showed that repeated cycles of dehydration-induced seismicity are likely in the midcrust where permeability is low. Because the fluid pressures can be near lithostatic, normal stress will decrease on both gently and steeply dipping faults. Ague $e t$ al. (1998) also argued that the low porosity of metamorphic rocks and the incompressibility of fluids facilitated rapid increases in pore pressure and triggering of earthquakes with minimal change in fluid volume. Further the volume of the Fillmore swarm was small or approximately only one cubic kilometer. Therefore, we conclude that properties of seismic waveforms such as attenuation or the presence of non-double-couple components of moment tensors are unlikely to reflect the presence of fluids in this case. 
To simulate the occurrence of hydroshear-induced seismicity, Aochi et al. (2013) developed a numerical model with heat and fluid migration, fault rheology, variable fault thickness, and shear rupture. Similar to the complexity observed in the Fillmore swarm, their model showed that the spatial and temporal seismicity patterns are strongly affected by dehydration rate and the presence of heterogeneous distribution of asperities.

To explain the limited rupture size of the fluid-induced swarm, Leclère et al. (2015) used both field evidence and numerical modeling to show how fluid overpressures in crustal fault zones develop and are maintained through elastic creep compaction. Creep compaction or aseismic creep can locally increase pore-fluid pressure, which in turn diffuses away and triggers seismicity. Such stresses can be small, on the order of 0.01-0.02 MPa (Leclère et al., 2015). To prevent a runaway rupture, a stabilization mechanism is required. Dilatant strengthening that consists of increase in porosity during accelerated sliding can cause a drop in pore pressure. In turn, the pore-pressure drop increases the effective normal stress and counteracts the instability (Leclère et al., 2015).

\section{DISCUSSION}

Southern California earthquake clusters exhibit a wide range of temporal, spatial, and moment release characteristics, ranging from simple to complex evolution in time, space, and magnitude (e.g., Vidale and Shearer, 2006). The simplest clusters are mainshock-aftershock sequences that exhibit rapid increase in moment release, follow Båth's law (Richter, 1958) with the mainshock magnitude $\sim 1.5$ units larger than the largest aftershock, have high-effective stress drop, and exhibit a temporal decay following the Omori law (Omori, 1907). In contrast, swarm sequences exhibit a gradual increase of moment release, deviate from Båth's law, have low effective stress drop, and, in some cases, exhibit slow Omori-like temporal decay (Roland and McGuire, 2009). The occurrence of swarms is usually explained with two different mechanisms, pressure front stress increase associated with fluid flow or aseismic creep on a slip surface, which both facilitate cascading failures of nearby asperities (Chen et al., 2012).

The 2015 Fillmore earthquake sequence exhibited many swarm-like characteristics, with gradual onset, low effective stress drop, and low migration speed. The slow migration speed of $0.003-0.06 \mathrm{~km} / \mathrm{hr}$ is consistent with a sequence of events in which fluid migration or an equivalent aseismic event propagated along the SSRF zone, or a nearby splay fault, bringing the state of stress closer to failure and triggering seismicity near a principal slip surface. The sudden onset of bursts of seismicity suggests the presence of cascading failures of asperities superimposed on slower fluid pressure migration. The coexistence of these driving mechanisms is expected because they provide positive feedback by increasing the permeability and by quickly transmitting fluid pressure, driving the seismicity migration (Shelly et al., 2015).
Although these types of swarms are relatively rare in the Ventura basin region, their occurrence is expected because of the high regional north-south compressive tectonic strains and presence of fluids in the basin sediments (Yang and Hauksson, 2013). Fluid pressures higher than hydrostatic levels have been interpreted from well logs but are only reported in the western basin (Watts, 1948; Hubbard et al., 2014). The 12.5-13.5 km depth of the Fillmore swarm agrees with the geodetically determined locking depth of major faults in the $\sim 12-13-\mathrm{km}-$ depth range (Marshall et al., 2013). The effective normal stress needs to be significantly reduced by near-lithostatic pore pressure to accommodate episodic slow-slip events at the depths of the Fillmore swarm, according to recent numerical models of slow-slip events at depth in subduction zones (Liu and Rice, 2009). We speculate that, near the bottom of the brittleductile transition zone as well as the basin sediments, metamorphic dehydration processes are likely to be very active, leading to both aseismic and seismic deformation processes (Yardley and Bodnar, 2014). However, because the earthquakes are small, it is not possible to detect non-double-couple components of the moment tensors, which could have confirmed a dilational component to the deformation. Similarly, small and deep aseismic slip events are unlikely to be detectable with available geodetic methods.

\section{CONCLUSIONS}

Geologic observations of dehydration metamorphic processes, modeling of fluid transport, and fault rheology argue for the role of fluids and cascading asperity failures in the 2015 Fillmore swarm. The relatively great depths beneath the Ventura basin sediments, limited spatial extent, diversity of focal mechanisms, and complex spatial and temporal behavior all suggest a role of fluids and cascading asperity failures. We infer that low porosity of metamorphic rocks and the incompressibility of fluids facilitated rapid increases in pore pressure and triggering of earthquakes with minimal change in fluid volume (Ague et al., 1998). However, the lack of similar seismicity in the exact same area over the last 35 years suggests that the fault-slip rates and associated dehydration processes may be very slow and that such events are rare.

The nodal planes of the focal mechanisms are inconsistent with the geometrical plane of the swarm, which could be the SSRF zone or a nearby splay fault. A major earthquake presumably would occur on a principal slip plane such as the SSRF, but elastic creep compaction may have limited the size of this swarm. The heterogeneous strain or slip partitioning between high-angle strike-slip faults and moderately dipping thrust faults suggests that, as fluids migrate toward regions of lower fluid pressures, this causes cascading ruptures of dip- and strikeslip faults localized by asperities.

\section{DATA AND RESOURCES}

We used waveforms and parametric data from the California Institute of Technology (Caltech)/U.S. Geological Survey 
Southern California Seismic Network (SCSN; doi: 10.7914/ $\mathrm{SN} / \mathrm{CI}$ ), stored at the Southern California Earthquake Data Center (SCEDC; doi: 10.7909/C3WD3xH1). \&

\section{ACKNOWLEDGMENTS}

We thank W. Thatcher for a comprehensive review and Thom Davis for helpful discussions. This research was supported by U.S. Geological Survey (USGS)/National Earthquake Hazards Reduction Program (NEHRP) Grant G15AP00095 and by the Southern California Earthquake Center (SCEC), which is funded by National Science Foundation Cooperative Agreement EAR1033462 and USGS Cooperative Agreement G12AC20038. This article is SCEC Contribution Number 6208. Google Earth imagery is used in the background of Figure 5.

\section{REFERENCES}

Ague, J. J., J. Park, and D. M. Rye (1998). Regional metamorphic dehydration and seismic hazard, Geophys. Res. Lett. 25, no. 22, 4221-4224.

Amitrano, D. (2003). Brittle-ductile transition and associated seismicity: Experimental and numerical studies and relationship with the $b$ value, J. Geophys. Res. 108, no. B1, 2044, doi: 10.1029/2001JB000680.

Aochi, H., B. Poisson, R. Toussaint, X. Rachez, and J. Schmittbuhl (2013). Self-induced seismicity due to fluid circulation along faults, Geophys. J. Int. 196, doi: 10.1093/gji/ggt356.

Behrmann, J. H., K. Brown, J. C. Moore, A. Mascle, E. Taylor, F. Alvarez, P. Andreiff, R. Barnes, and C. Beck (1988). Evolution of structures and fabrics in the Barbados accretionary prism. Insights from Leg 110 of the Ocean Drilling Program, J. Struct. Geol. 10, no. 6, 577-591.

Bilotti, F., and J. H. Shaw (2005). Deepwater Niger delta fold-and-thrust belt modeled as a critical-taper wedge: The influence of elevated basal fluid pressure on structural styles, Am. Assoc. Petrol. Geol. Bull. 89, no. $11,1475-1491$.

Brodsky, E. E., and J. Mori (2007). Creep events slip less than ordinary earthquakes, Geophys. Res. Lett. 34, L16309, doi: 10.1029/ 2007 GL030917.

Bryant, A. S., and L. M. Jones (1992). Anomalously deep crustal earthquakes in the Ventura basin, southern California, J. Geophys. Res. 97, 437-447.

Chen, X., and P. M. Shearer (2011). Comprehensive analysis of earthquake source spectra and swarms in the Salton trough, California, $J$. Geophys. Res. 116, no. B09309, doi: 10.1029/2011JB008263.

Chen, X., P. M. Shearer, and R. E. Abercrombie (2012). Spatial migration of earthquakes within seismic clusters in southern California: Evidence for fluid diffusion, J. Geophys. Res. 117, no. B04301, doi: 10.1029/2011JB008973.

Clinton, J. F., E. Hauksson, and K. Solanki (2006). An evaluation of the SCSN moment tensor solutions: Robustness of the $\mathrm{M}_{\mathbb{W}}$ magnitude scale, style of faulting, and automation of the method, Bull. Seismol. Soc. Am. 96, 1689-1705, doi: 10.1785/0120050241.

Davis, D., J. Suppe, and F. A. Dahlen (1983). Mechanics of fold-and thrust belts and accretionary wedges, J. Geophys. Res. 88, no. B2, $1153-1172$.

DeRito, R. F., A. H. Lachenbruch, T. H. Moses Jr., and R. J. Munroe (1989). Heat flow and thermotectonic problems of the central Ventura basin, southern California, J. Geophys. Res. 94, 681699, doi: 10.1029/JB094iB01p00681.

Hardebeck, J. L., and P. M. Shearer (2003). Using $S / P$ amplitude ratios to constrain the focal mechanisms of small earthquakes, Bull. Seismol. Soc. Am. 93, 2434-2444, doi: 10.1785/0120020236.

Hauksson, E., W. Yang, and P. M. Shearer (2012). Waveform relocated earthquake catalog for southern California (1981 to June 2011),
Bull. Seismol. Soc. Am. 102, no. 5, 2239-2244, doi: 10.1785/ 0120120010.

Hill, D. P. (1977). A model for earthquake swarms, J. Geophys. Res. 82, no. $8,1347-1352$.

Hubbard, J., J. H. Shaw, J. Dolan, T. L. Pratt, L. McAuliffe, and T. K. Rockwell (2014). Structure and seismic hazard of the Ventura Avenue anticline and Ventura fault, California: Prospect for large, multisegment ruptures in the western Transverse Ranges, Bull. Seismol. Soc. Am. 104, no. 3, 1070-1087, doi: 10.1785/0120130125.

Hubbert, M. K., and W. M. Rubey (1959). Role of fluid pressure in mechanics of overthrust faulting, Geol. Soc. Am. Bull. 70, 115-166.

Hutton, L. K., J. Woessner, and E. Hauksson (2010). Seventy-seven years (1932-2009) of earthquake monitoring in southern California, Bull. Seismol. Soc. Am. 100, no. 2, 423-446; doi: 10.1785/0120090130.

Leclère, H., F. Cappa, D. Faulkner, O. Fabbri, P. Armitage, and O. Blake (2015). Development and maintenance of fluid overpressures in crustal fault zones by elastic compaction and implications for earthquake swarms, J. Geophys. Res. 120, no. 6, 4450-4473, doi: 10.1002/2014JB011759.

Liu, Y., and J. R. Rice (2009). Slow slip predictions based on granite and gabbro friction data compared to GPS measurements in northern Cascadia, J. Geophys. Res. 114, no. B09407, doi: 10.1029/2008JB006142.

Malagnini, L., F. P. Lucente, P. De Gori, A. Akinci, and I. Munafo' (2012). Control of pore fluid pressure diffusion on fault failure mode: Insights from the 2009 L'Aquila seismic sequence, J. Geophys. Res. 117, no. B05302, doi: 10.1029/2011JB008911.

Marshall, S. T., G. J. Funning, and S. E. Owen (2013). Fault slip rates and interseismic deformation in the western Transverse Ranges, California, J. Geophys. Res. 118, doi: 10.1002/jgrb.50312.

Michael, A. J. (1984). Determination of stress from slip data: Faults and folds, J. Geophys. Res. 89, 11,517-11,526.

Nicholson, C., A. Plesch, C. Sorlien, J. H. Shaw, and E. Hauksson (2014). The SCEC 3D community fault model (CFM-v5): An updated and expanded fault set of oblique crustal deformation and complex fault interaction for southern California, Eos Trans. $A G U$ 95, no. 52, abstract T31B-4584.

Obligado, A., F. G. Ethridge, S. J. Sutton, W. R. Almon, and W. C. Dawson (2002). Sequence stratigraphy, shale characteristics, and potential for hydrocarbon seal development of the middle Eocene Juncal Formation, Ventura basin, southern California, Annual Meeting Expanded Abstracts, Am. Assoc. Petrol. Geol., 132.

Omori, F. (1907). Preliminary note on the course of the California earthquake of 1906, in The California Earthquake of 1906, D. S. Jordan (Editor), A. M. Robertson, San Francisco, California, 281-318.

Plesch, A, J. H. Shaw, C. Benson, W. A. Bryant, S. Carena, M. Cooke, J. Dolan, G. Fuis, E. Gath, L. Grant, et al. (2007). Community fault model (CFM) for southern California, Bull. Seismol. Soc. Am. 97, 1793-1802.

Raleigh, C. B., J. H. Healy, and J. D. Bredehoeft (1976). An experiment in earthquake control at Rangely, Colorado, Science 191, no. 4233, 1230-1237, doi: 10.1126/science.191.4233.1230.

Richter, C. F. (1958). Elementary Seismology, W.H. Freeman, San Francisco, California.

Roland, E., and J. J. McGuire (2009). Earthquake swarms on transform faults, Geophys. J. Int. 178, 1677-1690, doi: 10.1111/j.1365246X.2009.04214.x.

Shapiro, S. A., E. Huenges, and G. Borm (1997). Estimating the crust permeability from fluid-injection-induced seismic emission at the KTB site, Geophys. J. Int. 131, Fl5-Fl8.

Shaw, J. H., A. Plesch, C. Tape, M. P. Suess, T. Jordan, G. Ely, E. Hauksson, J. Tromp, T. Tanimoto, R. Graves, et al. (2015). Unified structural representation of the southern California crust and upper mantle, Earth Planet. Sci. Lett. 415, 1-15, doi: 10.1016/j. epsl.2015.01.016.

Shearer, P. M. (1998). Evidence from a cluster of small earthquakes for a fault at $18 \mathrm{~km}$ depth beneath Oak Ridge, southern California, Bull. Seismol. Soc. Am. 88, 1327-1336. 
Shelly, D. R., D. P. Hill, F. Massin, J. Farrell, R. B. Smith, and T. Taira (2013). A fluid-driven earthquake swarm on the margin of the Yellowstone caldera, J. Geophys. Res. 118, 4872-4886, doi: 10.1002/ jgrb.50362.

Shelly, D. R., S. C. Moran, and W. A. Thelen (2013). Evidence for fluidtriggered slip in the 2009 Mount Rainier, Washington earthquake swarm, Geophys Res. Lett. 40, 1506-1512, doi: 10.1002/grl.50354.

Shelly, D. R., T. Taira, S. G. Prejean, D. P. Hill, and D. S. Dreger (2015). Fluid-faulting interactions: Fracture-mesh and fault-valve behavior in the February 2014 Mammoth Mountain, California, earthquake swarm, Geophys. Res. Lett. 42, doi: 10.1002/2015GL064325.

Sibson, R. H. (1996). Structural permeability of fluid-driven faultfracture meshes, J. Struct. Geol. 18, no. 8, 1031-1042.

Thurber, C. H (1993). Local earthquake tomography: Velocities and $V_{P} / V_{S}$ theory, in Seismic Tomography: Theory and Practice, $\mathrm{H}$. M. Iyer and K. Hirahara (Editors), Chapman and Hall, London, United Kingdom, 563-583.

Uhrhammer, R. A., M. Hellweg, K. Hutton, P. Lombard, A. W. Walters, E. Hauksson, and D. Oppenheimer (2011). California integrated seismic network (CISN) local magnitude determination in California and vicinity, Bull. Seismol. Soc. Am. 101, 2685-2693, doi:10.1785/ 0120100106.

Vidale, J. E., and P. M. Shearer (2006). A survey of 71 earthquake bursts across southern California: Exploring the role of pore fluid pressure fluctuations and aseismic slip as drivers, J. Geophys. Res. 111, no. B05312, doi: 10.1029/2005JB004034.

Waldhauser, F., and W. L. Ellsworth (2000). A double-difference earthquake location algorithm: Method and application to the northern Hayward fault, Bull. Seismol. Soc. Am. 90, 1353-1368.

Watts, E. V. (1948). Some aspects of high pressures in the D-7 zone of the Ventura, Society of Petroleum Engineers, Trans. AIME 174, no. 01, 191-205, doi: 10.2118/948191-G.

Wiemer, S. (2001). A software package to analyze seismicity: ZMAP, Seismol. Res. Lett. 72, 373-382.

Winterer, E. L., and D. L. Durham (1962). Geology of the southeastern Ventura basin, Los Angeles County, California, U.S. Geol. Surv. Profess. Pap. 334-H, 275-366.

Yang, W., and E. Hauksson (2013). The tectonic crustal stress field and style of faulting along the Pacific North America plate boundary in southern California, Geophys. J. Int. 194, no. 1, 100-117, doi: $10.1093 /$ gji/ggt 113 .

Yang, W., E. Hauksson, and P. Shearer (2012). Computing a large refined catalog of focal mechanisms for southern California (1981-2010): Temporal stability of the style of faulting, Bull. Seismol. Soc. Am. 102, 1179-1194, doi: 10.1785/0120110311.

Yardley, B. W. D., and R. J. Bodnar (2014). Fluids in the continental crust, Geochem. Perspect. 3, 1-123.

Yeats, R. S. (1976). Neogene tectonics of the central Ventura basin, California, in A. E. Fritsche, H. Ter Best Jr., and W. W. Wornardt (Editors), The Neogene Symposium, Society of Economic Paleontologists and Mineralogists, Pacific Section, San Francisco, California.

Egill Hauksson Jennifer Andrews

California Institute of Technology Division of Geological and Planetary Sciences Seismological Laboratory Pasadena, California 91125 U.S.A. hauksson@caltech.edu

Andreas Plesch
John H. Shaw
Harvard University
Department of Earth and Planetary Sciences
20 Oxford Street
Cambridge, Massachusetts 02138 U.S.A.
David R. Shelly
U.S. Geological Survey
Volcano Science Center
Menlo Park, California 94025 U.S.A.

Published Online 18 May 2016 